\title{
Images from the Haematologica Atlas of Hematologic Cytology: dyserythropoiesis
}

\section{Rosangela Invernizzi}

University of Pavia, Pavia, Italy

E-mail: ROSANGELA INVERNIZZI - rosangela.invernizzi@unipv.it

doi:10.3324/haematol.2021.280385

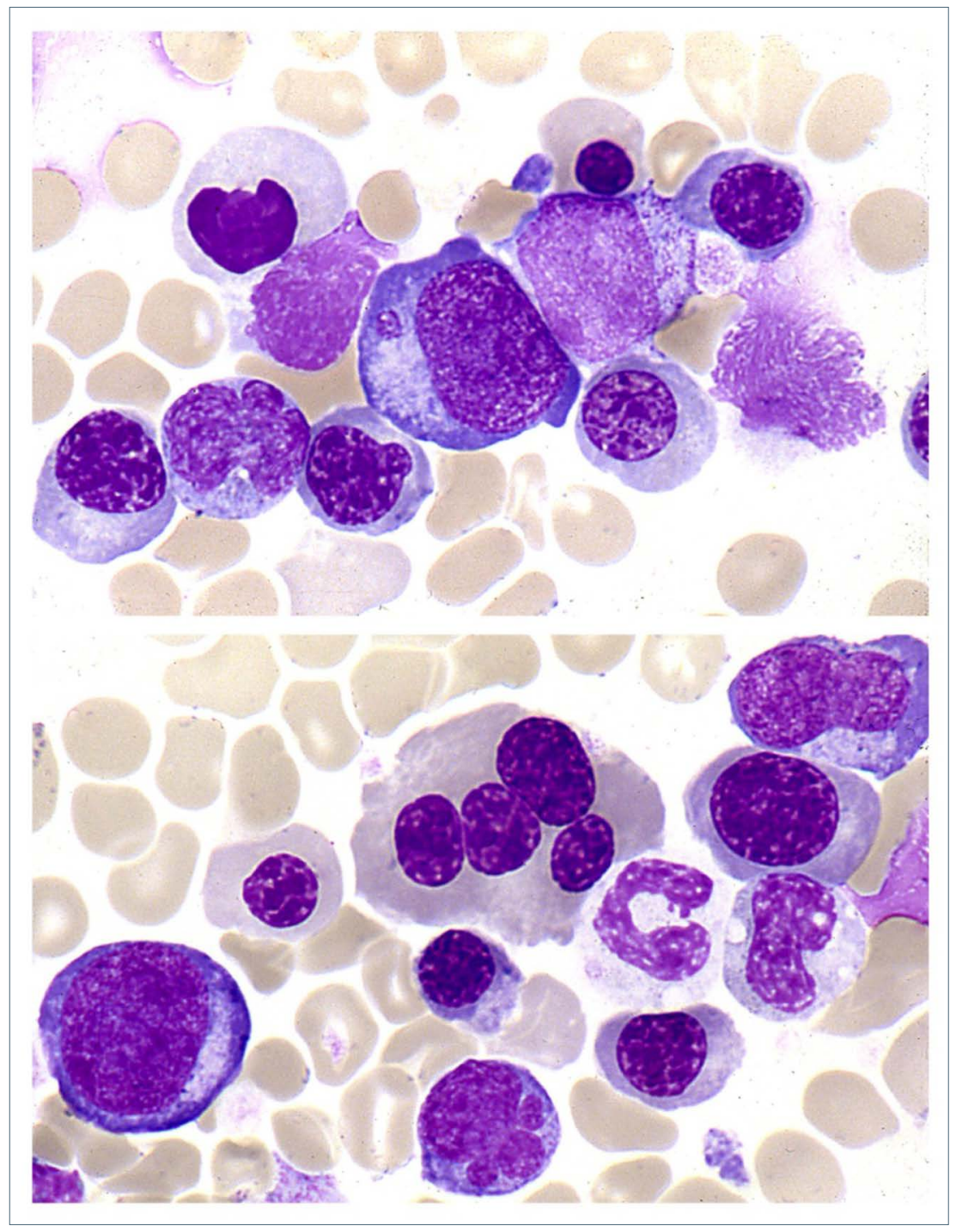

I he most frequently altered lineage in myelodysplastic syndromes is the erythroid one. Some of the morphological abnormalities of erythroid precursors are displayed in the Figure, showing representative bone marrow smears. In the top image erythroid hyperplasia with megaloblastoid changes is evident; in addition, note a detached nuclear fragment within the cytoplasm of an erythroblast (center) and a very large, late erythroblast with a pyknotic, irregularly shaped nucleus (top left). Giant multinucleated erythroblasts should also be considered dysplastic (bottom image), but variable degrees of dyserythropoiesis are commonly observed in various hematologic and non-hematologic disorders and have low diagnostic power. It is of critical importance that dyserythropoiesis is not assessed in isolation and, if dysplasia is confined to erythroid cells, other causes of erythroid dysplasia should be considered. ${ }^{1}$

\section{Disclosures}

No conflicts of interest to disclose

\section{Reference}

1. Invernizzi R. Myelodysplastic syndromes. Haematologica. 2020;105(Suppl 1):78-97. 